\title{
Investment guarantees in unit-linked life insurance from the customer perspective
}

\author{
Nadine Gatzert • Carin Huber · Hato Schmeiser
}

Published online: 14 October 2010

C) Springer-Verlag 2010

\begin{abstract}
Interest rate guarantees are a typical contract feature in unit-linked-life insurance products. As the financial crisis of 2007/2008 has shown, these guarantees can be of substantial value for policyholders since they ensure that at least a minimum amount will be paid back even if the mutual fund value falls below a specific guaranteed level. However, from the insurance company's view, these guarantees can be costly — especially in highly volatile markets - due to the required risk management measures which must be undertaken to secure the guarantees promised to the customers. Thus, the aim of this paper is to investigate whether customers really value these guarantees and if their willingness to pay (WTP) is sufficient to cover the guarantee costs. To elicit customer WTP, we use an online questionnaire and compare these results to the actual guarantee costs calculated with the Black and Scholes option pricing formula. One main finding is that even though most of the participants in the online questionnaire work in the financial industry, subjective prices are difficult to derive and are lower, on average, than the prices obtained using a financial pricing model. However, many participants are still willing to pay a substantially higher price.
\end{abstract}

This paper summarizes the main findings of the paper by Gatzert, Huber, and Schmeiser (2010) that was presented at the annual meeting of the German Association for Insurance Science in Düsseldorf in March 2010 and which is to appear in the Geneva Papers on Risk and Insurance. Details regarding the applied methods and the survey can be found in the original paper.

N. Gatzert

Chair for Insurance Economics, University of Erlangen-Nürnberg, Lange Gasse 20, 90403 Nürnberg, Germany

C. Huber $(\bowtie) \cdot$ H. Schmeiser

Institute of Insurance Economics, University of St. Gallen, Kirchlistrasse 2, 9010 St. Gallen,

Switzerland

e-mail: carin.huber@unisg.ch 
Zusammenfassung Fondsgebundene Lebensversicherungsprodukte enthalten mitunter Investmentgarantien in Form von Mindestverzinsungszusagen. Insbesondere in der Finanzkrise im Jahr 2007/2008 und den starken Verlusten in zahlreichen Anlageklassen wurde der Mehrwert dieser Art von Garantien für den Versicherungsnehmer unmittelbar sichtbar. Grundsätzlich ist für Versicherungsunternehmen die Gewährleistung solcher Garantien auf Basis adäquater Risikomanagementmassnahmen aufwändig und kostspielig. Somit stellt sich die Frage, inwieweit Kunden Finanzgarantien schätzen und ob deren Zahlungsbereitschaft ausreicht, um die beim Versicherer entstehenden Risikomanagementkosten zu decken. Die Zahlungsbereitschaft der Kunden wurde mittels einer Online-Umfrage erhoben. Die daraus resultierenden Ergebnisse wurden mit den auf optionspreistheoretischer Basis ermittelten Garantiekosten verglichen. Eines der Hauptergebnisse zeigt zum einen, dass obwohl der Grossteil der Befragten im Finanzdienstleistungssektor arbeitet die subjektive Zahlungsbereitschaft nur schwer abzuleiten ist. Zum anderen ist die durchschnittliche Zahlungsbereitschaft im Allgemeinen erheblich geringer als die auf Basis der Optionspreistheorie berechneten Mindestgarantiekosten. Dennoch ist ein gewisser Anteil der Befragten bereit, auch deutlich mehr als die Mindestgarantiekosten zu bezahlen.

\section{Introduction}

Against the background of the demographic development, the demand for pension products will most probably increase in the future. In addition, a current customer trend in favor of unit-linked products can be observed. These products allow-by means of the underlying mutual fund-participation in positive market developments, but also bring the risk of a low return in times of capital market crises. Hence, one increasingly important aspect in the design of long-term unit-linked life insurance contracts is financial guarantees, which ensure a minimum payoff at maturity. Thus, on the one hand, customers require the chance to participate in positive market development, and on the other hand appreciate the safety aspects of the product. The value of such guarantees from the viewpoint of policyholders can be substantial, as has been demonstrated in the case of the British life insurer Equitable Life, which had to close to new business in December 2000 due to an inadequate reserving and pricing of a guaranteed annuity option embedded in with-profit life insurance contracts.

Thus, financial guarantees can be very valuable but represent a substantial risk from the insurer's perspective. An adequate pricing is essential to obtain sufficient funds to conduct risk management. However, customer evaluation may be quite different from what financial theory suggests. In general, financial guarantees in unitlinked life insurance policies can be evaluated in different ways, depending on the perspective of the insurer or the customer. In particular, while an insurer may generally be able to determine an adequate premium for financial guarantees based on a replication of contractual cash flows, such as risk-neutral valuation and other premium principles, customers may not necessarily be able to replicate their claims but instead assess the value of guarantees based on individual preferences. The aim of the paper presented by Gatzert et al. (2010) is to contrast both perspectives by comparing the subjective willingness to pay of customers with the theoretical price from the insurer's perspective based on risk-neutral valuation. 
The theoretical background of behavioral insurance is first presented, based on Kahneman and Tversky's (1979) prospect theory (Sect. 2). Second, the fair price of a minimum guarantee embedded in a unit-linked insurance contract is determined as the minimum premium an insurer needs to charge in order to secure the guarantee with risk management measures (Sect. 3). Third, the setup and main results of the empirical survey to identify customer WTP for financial guarantees are discussed in Sect. 4 along with resulting implications, and, finally, a summary and discussion of policy implications are given in Sect. 5.

\section{Theoretical background: behavioral insurance and customer willingness to pay}

\subsection{Prospect theory and behavioral insurance}

People use different mental models when making decision, especially with respect to risky or probabilistic choices, and these mental models are often inconsistent with the basic principles of expected utility theory. The previous literature in the area of behavioral economics has revealed irrationalities in decision making, such as heuristics and biases that do not harmonize with expected utility theory (for an overview, see, e.g., Camerer and Loewenstein 2003). Based on this irrational behavior, Kahneman and Tversky (1979) began to contradict expected utility theory with prospect theory in their work. They developed the following value function which reflects this contradictory behavior. Figure 1 shows, that this value function $v$ is concave for $x>0\left(v^{\prime \prime}(x)<0\right)$, convex for $x<0\left(v^{\prime \prime}(x)>0\right)$, steeper for losses than for gains, and steepest at the reference point (hence, $v^{\prime}(x)<v^{\prime}(-x)$ for $x \geq 0$ ). Furthermore, Tversky and Kahneman (1992) extend these considerations in their concept of cumulative prospect theory, Loewenstein and Prelec (1992) develop their model of intertemporal choice and many biases and heuristics have been examined since this theoretical breakthrough (Tversky and Kahneman 1974).

The purchase of insurance contracts leads to a substantial amount of irrational behavior due to its risky and probabilistic outcomes. ${ }^{1}$ In addition, insurance demand has been studied using experimental analyses. Using prospect theory, Wakker et al. (1997) explain experimental data on the demand for probabilistic insurance policies, which accounts for the insolvency risk of an insurer by indemnifying the policyholder with a probability of strictly less than 1 . Further experimental research on insurance demand under default risk was conducted by Albrecht and Maurer (2000), Zimmer et

\footnotetext{
${ }^{1}$ The mental models believed to be in play during insurance purchase decisions include the following: anchoring, i.e., the adjustment on an initial value (Tversky and Kahneman 1974); an availability bias, i.e., the evaluation depends on how easily something comes to mind (Tversky and Kahneman 1973); a certainty effect, i.e., the overweighting of certain outcomes relative to probable outcomes (Allais 1953; Tversky and Wakker 1995); framing, i.e., reliance on how information is presented (Tversky and Kahneman 1981, 1986; Kahneman and Tversky 1984); loss aversion, i.e., losses loom larger than corresponding gains (Tversky and Kahneman 1991); mental accounting, i.e., the dividing of current and future assets into separate, nontransferable portions (Thaler 1999); wishful thinking, and overconfidence, e.g., by overestimating own knowledge and ability to control events, while underestimating risks (Barberis and Thaler 2005); risk perception (Slovic 1972; Slovic et al. 1977) or an overestimation of probabilities (Johnson et al. 1993).
} 
Fig. 1 Value function of prospect theory (Kahneman and Tversky 1979)

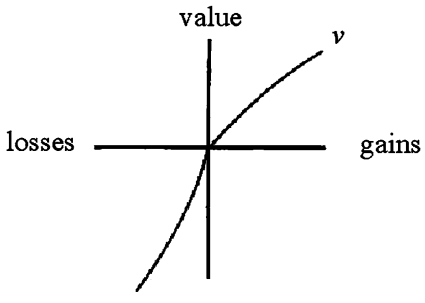

al. $(2008,2009)$, who show that awareness of even a very small positive probability of insolvency considerably reduces customer willingness to pay (WTP). Gatzert et al. (2009) compare prices for participating life insurance contracts determined via financial theory with prices determined via expected utility theory, thus combining policyholder and insurer perspectives. Except for this study, previous literature on behavioral insurance has focused on the impact of insurer default risk on customer WTP.

\subsection{Customer willingness to pay}

The research field of measuring customer willingness to pay comprises numerous approaches based on differential conceptual foundations and methodological implications. However, each approach has its own strengths and limitations. Thus, none of them is perfectly able to measure WTP, see Breidert et al. (2006). An overview of methods for measuring consumer WTP can be found in Miller et al. (2010) or Diller (2000). In this study, we use a direct survey method. Although measuring WTP directly in general is a highly cognitive demanding task and might lack some validity and reliability (see, e.g., Wertenbroch and Skiera 2002; Breidert et al. 2006; Völckner 2005,2006 ), we use this approach and compensate for its limitations in the following way: We use a specific to compensate for the limitations of the direct approach, we use a specific sample with finance or insurance background and give only tentative results and implications. Furthermore, we refer to Wakker et al. (1997) who used this approach in order to measure the WTP for probabilistic insurance products. In addition to measuring WTP, a direct approach provides first insights regarding consumers' price knowledge and the understandability of investment guarantees in unit-linked life insurance (Vanhuele and Drèze 2002).

The presented paper extends this research by examining customer WTP to prevent their maturity payoff of a unit-linked life insurance contract from falling below a minimum guarantee level. In particular, the gap between the value of guarantees in unit-linked life insurance based on duplication of cash flow-from the insurer perspective - and the value of guarantees from the customer perspective— based on an empirical survey-is studied.

\section{Valuation of investment guarantees in unit-linked life insurance products in a black-scholes-framework}

The theoretical price of an investment guarantee is obtained based on a model of a unit-linked life insurance policy as is done in, e.g., Gatzert and Schmeiser (2009) 
Table 1 Overview of surveyed products and product characteristics

\begin{tabular}{|c|c|c|c|c|c|c|c|}
\hline \multirow[t]{2}{*}{ Product } & \multirow{2}{*}{$\begin{array}{l}\text { Up-front } \\
\text { premium } \\
\text { (savings } \\
\text { part) in } \\
\text { CHF }\end{array}$} & \multirow{2}{*}{$\begin{array}{l}\text { Contract } \\
\text { term in } \\
\text { years }\end{array}$} & \multirow{2}{*}{$\begin{array}{l}\text { Risk level } \\
\text { of mutual } \\
\text { fund }\end{array}$} & \multicolumn{2}{|c|}{$\begin{array}{l}\text { Guarantee I ( } 0 \% \text { interest } \\
\text { rate, money-back) }\end{array}$} & \multicolumn{2}{|c|}{$\begin{array}{l}\text { Guarantee II ( } 2 \% \\
\text { interest rate) }\end{array}$} \\
\hline & & & & $\begin{array}{l}\text { Guaranteed } \\
\text { minimum } \\
\text { payment in } \\
\mathrm{CHF}\end{array}$ & $\begin{array}{l}\text { Guarantee } \\
\text { costs in } \\
\text { CHF }\end{array}$ & $\begin{array}{l}\text { Guaranteed } \\
\text { minimum } \\
\text { payment in } \\
\text { CHF }\end{array}$ & $\begin{array}{l}\text { Guarantee } \\
\text { costs in } \\
\mathrm{CHF}\end{array}$ \\
\hline A & 10,000 & 10 & medium & 10,000 & 298 & 12,214 & 1,000 \\
\hline B & 10,000 & 10 & high & 10,000 & 1,117 & 12,214 & 2,060 \\
\hline $\mathrm{C}$ & 50,000 & 10 & medium & 50,000 & 1,491 & 61,070 & 5,015 \\
\hline $\mathrm{D}$ & 10,000 & 20 & medium & 10,000 & 204 & 14,918 & 1,365 \\
\hline
\end{tabular}

and Lachance and Mitchell (2003). ${ }^{2}$ Focus is placed exclusively on the value of the financial guarantee and, thus, no death benefit or options to early exercise are included in the contract design. Furthermore, administrative costs are ignored, such that the price obtained can rather be considered as a lower limit to the actual guarantee price. The procedure to calculate the price and the input parameters used for the empirical survey are as follows.

The customer is assumed to pay a single up-front premium of CHF 10,000, which is invested in a mutual fund for a contract term of 10 years. The underlying mutual fund is modeled using a geometric Brownian motion with fixed average rate of return and standard deviation during the contract term. The unit-linked product studied in the survey is based on a mutual fund that invests in the money market and in stocks. We therefore compared the case of a "medium-risk" mutual fund that invests $50 \%$ in the money market and 50\% in stocks with a "high-risk" mutual fund that invests $100 \%$ in stocks. The medium-risk fund has an expected return of $4.061 \%$ and a volatility $\sigma=8.610 \%$; the high-risk fund has an expected return of $5.975 \%$ and a volatility of $\sigma=17.220 \%$ (input data were estimated from the Swiss market indices).

Since the contract payoff is stochastic and depends on the development of financial markets over time, the terminal investment value can fall below the initially paid premium. To prevent such a default situation for the policyholder, the customer can additionally acquire a minimum interest rate guarantee on the premium (in the following $0 \%$, i.e., a money-back guarantee, and a $2 \%$ interest rate guarantee). The premium for this guarantee has to be paid in addition to the single up-front premium and represents the minimum amount an insurer needs to charge to be able to conduct adequate risk management to ensure the guarantee provided to the customer.

Pricing is conducted using risk-neutral valuation. Since the payoff to the customer can be written as the value of the underlying assets plus a put option on this value with strike price equal to the minimum guarantee, ${ }^{3}$ the Black-Scholes European put option pricing formula can be applied to obtain a closed-form solution for the premium. An overview of resulting prices for the different products compared in the survey and the input parameters listed above is provided in Table 1.

\footnotetext{
${ }^{2}$ For details and formal representations of the model framework see Gatzert et al. (2010).

${ }^{3}$ See Gatzert et al. (2010).
} 
As illustrated in Table 1, the survey comprises four products: In addition to distinguishing a medium- from a high-risk fund, two guarantee levels are compared, including the money-back guarantee (Guarantee I) and a minimum interest rate of $2 \%$ on the initial nominal premium (Guarantee II), the initial premium is increased from $\mathrm{CHF} 10,000$ to $\mathrm{CHF} 50,000$ and the contract duration is extended from 10 years to 20 years.

\section{Valuation of investment guarantees in unit-linked life insurance products in an empirical survey}

\subsection{Design of the survey, sample, and survey procedure}

In the empirical survey, objective (Table 1) and subjective prices for investment guarantees in unit-linked life insurance products are contrasted using a computer-based questionnaire comprised of direct open-response questions regarding the willingness to pay for the four products shown in Table 1, a section containing choice options, and questions as to the respondent's age, gender, and knowledge about insurance. ${ }^{4}$ Based on pre-tests, the questionnaire was revised and potential biases eliminated or controlled for as much as possible. ${ }^{5}$

To account for the complexity of unit-linked life insurance products, the desired sample was mainly composed of people having some relation to insurance or finance, and is thus in tendency more capable of stating WTP for guarantees directly. The sample was obtained by conducting the empirical survey among 2,500 people in the contact database of the Institute of Insurance Economics at the University of St. Gallen, who are thus mainly working in the financial services industry or in the insurance and finance departments of universities. After a two-week period from May 20, 2009 to June 2, 2009, 375 people had completed the survey, a completion rate of $14.5 \%$. After removing 15 outliers from the sample, the total sample size was $360 .^{6}$

The survey was divided into three parts. In the first part, participants were asked to state their WTP for an additional investment guarantee for the different products listed in Table 1, explaining that the cost for the protection of default would have to be paid on top of the single up-front premium CHF 10,000 invested in the mutual fund. To avoid framing effects due to the payoff presentation (verbally, numerically, graphically, positively, or negatively), information was presented as neutrally as possible by providing a graphical illustration of the terminal payoff and the probabilities

\footnotetext{
${ }^{4}$ For an overview of methods for measuring consumer WTP, see Diller (2000) and Völckner (2005, 2006). A detailed description of the empirical survey is given in Gatzert et al. (2010).

${ }^{5}$ Biases that were eliminated or controlled included (a) the availability bias-dealt with by concentrating on an insurance- or finance-related sample, (b) framing effects, risk perception, and overestimation of probabilities - dealt with by using graphical, verbal, and numerical illustrations of the probabilities (see Fig. 3), and (c) anchoring-dealt with by the order of the questions.

${ }^{6}$ The reasons for elimination were: (a) obviously false statements concerning WTP, possibly due to a desire to move on to the next question in the survey (e.g., 123456) and (b) disproportionate overestimation of WTP, possibly due to the question being too difficult for the particular participant to understand (e.g., WTP twice as high as the initial premium invested in the fund).
} 
accompanied by a written explanation. Due to the difficulties associated with a direct statement of WTPs of guarantee costs and the implied high volatility of responses (Völckner 2006), the second part of the survey included multiple-choice questions among three products (no guarantee, money-back guarantee, and 2\% minimum interest rate in the case) for medium- and high-risk funds, thereby providing the guarantee prices obtained by option pricing theory. Since the choice questions were posed after directly asking for WTP and participants could not change their answers to the judgment question after reading the choice questions with the calculated guarantee prices, possible anchoring effects were avoided. Finally, in the third part, information on gender, age, job, education, attitude toward risk, stock ownership, knowledge about guarantees in life insurance products, and previous purchase of pension or life insurance products were collected.

\subsection{Sample description}

An examination of the first part of the study shows that the majority of the respondents are male, have experience with the stock market, an educational and job profile related to insurance and finance, and consider themselves as risk- neutral or even risk-seeking. Even though all survey participants have some connection to insurance and finance, one-fifth does not own a pension or life insurance product other than obligatory state pension schemes. However, most participants own one or multiple contracts, more than half of which are unit-linked.

\subsection{Customer willingness to pay (WTP)}

In the following, the main results of the WTP are displayed with focus on the four products displayed in Table 1. Further analyses and statistics (including mean, median, and standard deviation) can be found in Gatzert et al. (2010). Table 2 contains descriptive statistics of WTP for the different product designs described in Table 1 and contrasts them with the guarantee costs based on option pricing theory.

The results reveal that the average WTP of respondents is considerably lower than the minimum price an insurer would have to charge based on option pricing theory. A two-sided t-test on whether the average WTP significantly differs from the insurer's

Table 2 Subjective mean WTP of all participants versus mean WTP of participants with positive WTP

\begin{tabular}{|c|c|c|c|c|c|c|}
\hline \multirow[t]{2}{*}{ Product } & \multicolumn{3}{|c|}{$\begin{array}{l}\text { Guarantee I ( } 0 \% \text { interest rate, money-back } \\
\text { guarantee) }\end{array}$} & \multicolumn{3}{|c|}{ Guarantee II ( $2 \%$ interest rate) } \\
\hline & $\begin{array}{l}\text { Guarantee } \\
\text { costs }\end{array}$ & $\begin{array}{l}\text { Mean WTP } \\
\text { of all par- } \\
\text { ticipants } \\
(n=360)\end{array}$ & $\begin{array}{l}\text { Mean WTP } \\
\text { in CHF } \\
\text { of participants } \\
\text { with WPT >0 }\end{array}$ & $\begin{array}{l}\text { Guarantee } \\
\text { costs }\end{array}$ & $\begin{array}{l}\text { Mean WTP } \\
\text { of all par- } \\
\text { ticipants } \\
(n=360)\end{array}$ & $\begin{array}{l}\text { Mean WTP } \\
\text { in CHF } \\
\text { of participants } \\
\text { with WPT >0 }\end{array}$ \\
\hline A & 298 & 219 & $294(n=268)$ & 1,003 & 516 & $582(n=319)$ \\
\hline B & 1,117 & 401 & $489(n=295)$ & 2,057 & 788 & $876(n=324)$ \\
\hline $\mathrm{C}$ & 1,491 & 1,045 & $1,330(n=283)$ & 5,015 & 2,344 & $2,613(n=323)$ \\
\hline D & 204 & 206 & $326(n=227)$ & 1,363 & 603 & $724(n=300)$ \\
\hline
\end{tabular}


minimum OPT price reveals that this mispricing or underestimation is significant ( $\mathrm{p}$ value $=0.00 \%$ ), except for Product $\mathrm{D}$ for the longer contract term of 20 years in the case of a money-back guarantee, in which case the subjective price is almost equal to the theoretical price.

Table 2 also displays information on the subsample with a positive WTP (right columns), which reveals that between $10 \%$ and $37 \%$ of the participants (depending on the product design) are not willing to pay a positive amount for an additional guarantee. However, in the case of a money-back guarantee for Product A (medium risk fund), the subjective WTP is almost the same as the theoretical guarantee costs, and for a contract term of 20 years (Product D), the WTP of CHF 326 on average significantly exceeds the price calculated using option pricing theory (CHF 204). Even though all other product designs show a subjective WTP that is significantly less than the OPT model price, the average WTP is significantly higher when increasing the guarantee level and when switching from a medium-risk fund to a high-risk fund (based on a one-sample t-test). In addition, for all product types, more participants have a positive WTP for Guarantee II than for Guarantee I. At the same time, the WTP of those who are willing to pay for Guarantee $\mathrm{I}$ is always closer to the theoretical model price than the WTP of those willing to pay for Guarantee II, which is also true for the fund with medium risk. This implies that the value of a higher guarantee level and the increase in value when using a high-risk fund is severely underestimated. Further analysis shows a high standard deviation of the responses, which confirms the expected difficulties for directly stating the WTP, even in this fairly knowledgeable sample.

\subsection{Customers' product choice}

To obtain a more comprehensive picture of customer preferences, the second part of the survey asked participants to choose among three unit-linked products, given the theoretical guarantee costs, including the case without an additional guarantee, with a money-back guarantee and a $2 \%$ interest rate guarantee. The findings are displayed in Table 3.

Consistent with the findings from Table 2 and the significant underestimation of the theoretical guarantee costs, a large part of the participants chose Product 1 without any additional guarantee. However, at the same time, more than half decided in favor of Products 2 and 3, and thus, chose an additional guarantee, whereby more participants preferred the money-back guarantee. The results do not substantially differ when comparing the results for the underlying medium- and the high-risk fund.

Table 3 Choice among three unit-linked life insurance products given option pricing model prices; absolute frequency, percentage in parentheses

\begin{tabular}{llll}
\hline & $\begin{array}{l}\text { Product 1: no } \\
\text { guarantee no } \\
\text { additional costs }\end{array}$ & $\begin{array}{l}\text { Product 2: money-back } \\
\text { guarantee CHF 300 (for } \\
\text { medium risk) CHF 1,000 } \\
\text { (for high risk) }\end{array}$ & $\begin{array}{l}\text { Product 3: 2\% interest rate } \\
\text { guarantee CHF 1,120 (for } \\
\text { medium risk) CHF 2,060 } \\
\text { (for high risk) }\end{array}$ \\
\hline $\begin{array}{l}\text { Medium-risk fund } \\
\text { High-risk fund }\end{array}$ & $\begin{array}{l}157(44 \%) \\
160(44 \%)\end{array}$ & $\begin{array}{l}124(34 \%) \\
117(33 \%)\end{array}$ & $\begin{array}{l}79(22 \%) \\
83(23 \%)\end{array}$ \\
\hline
\end{tabular}


Nevertheless, the WTP was generally higher for higher guarantee levels, on average. No participant chose a product in the third part of the study that exceeded his or her WTP, which indicates that price is the main factor that discourages customers from buying a guarantee.

\section{Summary and outlook}

The aim of the Gatzert et al. (2010) paper-a summary of the version that was presented at the annual meeting of the German Association for Insurance Science in Düsseldorf in March 2010-is to compare prices for investment guarantees for unitlinked life insurance based on option pricing theory with subjective WTP. To derive these subjective WTP, we administered an online questionnaire comprising direct open-response questions and multiple-choice options. The majority of the participants had some connection to either insurance or finance.

The results of this study show that the average WTP of customers for investment guarantees in unit-linked life insurance products is in general much lower than the reservation price the insurer should charge at minimum. However, a substantial portion of participants had a WTP that considerably exceeded the insurer's reservation price. Customer characteristics had almost no influence on the WTP, and differences among the groups could hardly be observed. Furthermore, the participants in the survey found it difficult to directly assess "true" subjective WTP for insurance-related guarantees, even though the sample is specialized in finance or insurance. This finding was confirmed when considering the considerable deviations of the stated WTP and the high number of outliers, which makes a direct assessment of "true" subjective prices for guarantees very difficult.

Due to the non-representative selection of the sample and the limited validity and reliability in the direct approach, our findings and their implications cannot be generalized. However, even though interpretations and policy implications are tentative, the present research provides first information in respect to practical implications for insurers. First, and as pointed out earlier, insurance products are very complex, and customers may not be willing or able to fully understand these products or their individual components, much less evaluate or compare them. Consequently, the question arises, if it is advisable and justifiable to offer rather complex products instead of a transparent product design that may increase customer value. Second, on average, the WTP for investment guarantees does not cover the reservation price. Thus, the question arises to what extent the product design considers customer preferences and, more specifically, the trade-off between the wish for high guarantees (and thus a secure payoff at maturity) and the associated costs. Third, regulatory authorities and tax subsidies generally obligate people to buy guarantees, even if customers may not be willing to buy and pay for all of these guarantees. Thus, regulatory authorities should reflect requirements in regard to guarantees in light of insurance customers' interests.

\section{References}

Albrecht, P., Maurer, R.: Zur Bedeutung der Ausfallbedrohtheit von Versicherungskontrakten - ein Beitrag zur Behavioral Insurance. ZVersWiss 89, 339-355 (2000) 
Allais, M.: Le comportement de l'homme rationnel devant le risque: critique des postulats et axiomes de l'ecole americaine. Econometrica 21(4), 503-546 (1953)

Barberis, N., Thaler, R.: A survey of behavioral finance. In: Thaler, R. (ed.) Advances in Behavioral Finance, vol. II, pp. 1-76. Princeton University Press, Princeton (2005)

Breidert, C., Hahsler, M., Reutterer, T.: A review of methods for measuring willingness-to-pay. Innov. Mark. 2(4), 8-32 (2006)

Camerer, C.F., Loewenstein, G.: Behavioral economics: past, present, future. In: Camerer, C.F., Loewenstein, G., Rabin, M. (eds.) Advances in Behavioral Economics, pp. 3-52. Princeton University Press, Princeton (2003)

Diller, H.: Preispolitik. Kohlhammer, Stuttgart (2000)

Gatzert, N., Schmeiser, H.: Pricing and performance of mutual funds: lookback versus interest rate guarantees. J. Risk 11(4), 31-49 (2009)

Gatzert, N., Holzmueller, I., Schmeiser, H.: Creating customer value in participating life insurance. Working Paper on Risk Management and Insurance, University of St. Gallen (2009)

Gatzert, N., Huber, C., Schmeiser, H.: On the valuation of investment guarantees in unit-linked life insurance: a customer perspective. In: Geneva Papers on Risk and Insurance (2010, to appear)

Johnson, E., Hershey, J., Meszaros, J., Kunreuther, H.: Framing, probability distortions, and insurance decisions. J. Risk Uncertain. 7(1), 35-51 (1993)

Kahneman, D., Tversky, A.: Prospect theory: an analysis of decision under risk. Econometrica 47(2), 263291 (1979)

Kahneman, D., Tversky, A.: Choices, values, and frames. Am. Psychol. 39(4), 341-350 (1984)

Lachance, E.-M., Mitchell, O.S.: Understanding individual account guarantees. Am. Econ. Rev. 93(2), 257-260 (2003)

Loewenstein, G., Prelec, D.: Anomalies in intertemporal choice: evidence and an interpretation. Q. J. Econ. 107(2), 573-579 (1992)

Miller, K., Hofstetter, R., Krohmer, H., Zhang, J.: How should we measure consumers' willingness to pay? An empirical comparison of state-of-the-art approaches. J. Mark. Res. (2010, forthcoming)

Slovic, P.: Psychological study of human judgment: implications for investment decision making. J. Finance 27(4), 779-799 (1972)

Slovic, P., Fischhoff, B., Lichtenstein, S., Corrigan, B., Combs, B.: Preference for insuring against probable small losses: insurance implications. J. Risk Insur. 44(2), 237-258 (1977)

Thaler, R.H.: Mental accounting matters. J. Behav. Decis. Mak. 12(3), 183-206 (1999)

Tversky, A., Kahneman, D.: Availability: a heuristic for judging frequency and probability. Cogn. Psychol. 5, 207-232 (1973)

Tversky, A., Kahneman, D.: Judgment under uncertainty: heuristics and biases. Science 185(4157), 11241131 (1974)

Tversky, A., Kahneman, D.: The framing of decisions and the psychology of choice. Science 211(4481), 453-458 (1981)

Tversky, A., Kahneman, D.: Rational choice and the framing of decision. J. Bus. 59(4/2), S251-S278 (1986)

Tversky, A., Kahneman, D.: Loss aversion in riskless choice: a reference-dependent model. Q. J. Econ. 106(4), 1039-1061 (1991)

Tversky, A., Kahneman, D.: Advances in prospect theory: cumulative representation of uncertainty. J. Risk Uncertain. 5(4), 297-323 (1992)

Tversky, A., Wakker, P.: Risk attitudes and decision weights. Econometrica 63(6), 1255-1280 (1995)

Vanhuele, M., Drèze, X.: Measuring price knowledge shoppers bring to the store. J. Mark. 66(2), 72-85 (2002)

Völckner, F.: Biases in measuring consumers' willingness to pay. Working Paper on Marketing and Retailing, University of Hamburg (2005)

Völckner, F.: Methoden zur Messung individueller Zahlungsbereitschaften: Ein Überblick zum State of the Art. J. Betriebswirtsch. 56(1), 33-60 (2006)

Wakker, P.P., Thaler, R.H., Tversky, A.: Probabilistic insurance. J. Risk Uncertain. 15(1), 7-28 (1997)

Wertenbroch, K., Skiera, B.: Measuring consumers' willingness to pay at the point of purchase. J. Mark. Res. 39(2), 228-241 (2002)

Zimmer, A., Gründl, H., Schade, C.: Default risk, demand for insurance, and optimal corporate risk strategy of insurance companies. Working Paper, Humboldt-Universität zu Berlin, School of Business and Economics (2008)

Zimmer, A., Schade, C., Gründl, H.: Is default risk acceptable when purchasing insurance? Experimental evidence for different probability representations, reason for default, and framings. J. Econ. Psychol. 30(1), 11-23 (2009) 